\title{
Application of Blockchain Technology in the Field of Accounting Supervision
}

Xianrui Hou*

Zhejiang University of Finance \& Economics Dongfang College, Jiaxing 314408, China. E-mail: 122648739@qq.com

\begin{abstract}
Accounting supervision, one of the most basic functions of accounting, plays an extremely important role in accounting subject. As a new term in the field of information technology, blockchain technology has been continuously developed and improved in recent years, and it has gradually become a social focus. This paper introduces that blockchain can supervise accounting more effectively with its characteristics of openness, transparency, de credit, tamper proof and timing. Accounting supervision is a guarantee system to improve the quality of accounting information, but in recent years, due to the weakening of the ability of accounting supervision, financial fraud occurs from time to time. Because accounting supervision is not enough, accounting information is distorted and capital market is confused. Therefore, this paper analyzes the application of new information technology combined with accounting supervision, the reasons for weakening and the solutions.
\end{abstract}

Keywords: Blockchain Accounting Supervision Open and Transparent

\section{Concept of blockchain technology}

Blockchain technology is a distributed structure, just like "shared account book". When each node after the transaction is verified to be effective and error free, the transaction will be included in the specified block. At the same time, the block will also be synchronized to all nodes, and the chain structure will be formed in chronological order, then each node will be fully backed up by the generated blockchain. This "shared account book" was formed ${ }^{[1]}$.

In the whole system, each step fully shows the characteristics of blockchain, and each node protects the security and anti-counterfeiting of data. In the transaction, there is no need for third-party credit to ensure the validity, security and authenticity of the data. It also aims at preventing the data from being maliciously edited and forged and improving the work efficiency. Because each data will be synchronized to each node, if there is a small change in the data, it will affect each node or even the whole system. On the other hand, with its open and transparent characteristics, it also prevents the data from being compiled, thus ensuring the authenticity and security of the data ${ }^{[2]}$.

The structure is as follows: 


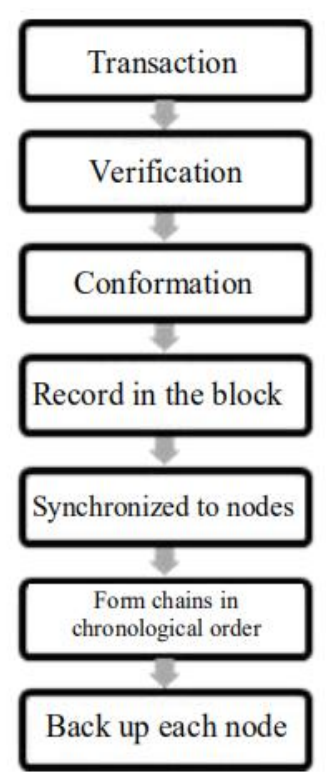

\section{Application path of blockchain technology}

As the hottest technology in the field of Internet finance, blockchain, with its characteristics of decentralization, openness, transparency and anti editing, has shown the strongest advantage in many fields, including finance, Internet of Things, insurance, public welfare, etc., and it has brought positive influence to various fields to a certain extent.

\subsection{Open and transparent}

For enterprises that use the "shared account book" function, the evidence of each business transaction between each enterprise is recorded in the form of blocks, each node is synchronized and connected into a chain according to the time sequence. Then the staff only need to track these timestamps in front of the computer to audit the blockchain. Because the blockchain technology is highly open and transparent, staff and transaction related enterprises can see all the information of the enterprise's book, so the book information of any related transaction between enterprises can not be hidden, which greatly reduces the work of data collection, as well as the cost of labor and time.

\subsection{Blockchain information system can effectively prevent the occurrence of financial accounting information distortion}

At the time of transaction, each node needs to carry out validity verification, and only when it is confirmed to be correct can it be included in the block, which can effectively reduce the probability of information distortion and fraud In the blockchain, what happens at a certain time point in each block will be recorded on the blockchain, which cannot be modified by anyone, and it is irreversible. Therefore, the authenticity and security of financial accounting information have been greatly improved by the block chain.

\section{Reasons for the weakening of accounting supervision}

Accounting supervision refers to the supervision of accounting work in accordance with national laws and various financial policies, rules and regulations, and the comprehensive coordination, control, supervision and supervision of economic activities with correct accounting information, so as to achieve the purpose of improving economic benefits. The important reason for the distortion of accounting information is the weakening of accounting supervision, while the distortion of accounting information leads to the crisis of accounting integrity, which shows that the legal system of accounting supervision in China is not perfect, leading to no strict legal constraints. The forms of weakening of accounting supervision function are diverse, and the causes are different. 


\subsection{Enterprise accounting and internal audit information system is not perfect}

As far as the current accounting system in China is concerned, the accounting legal system is still imperfect. If the system is not perfect, there will be interest temptation for the accountant in charge of the accounting firm, and the accountant is required to change the actual economic activities of the enterprise. In this way, there will be accounting asymmetry. Virtual financial situation is difficult to realize the function of accounting supervision.

\subsection{Lack of a sound audit information system within the enterprise}

The operation of audit information system includes obtaining information, processing information, storing information and transmitting information. In the whole information process of audit implementation, the supervision department pays too much attention to the results and it ignores the inspection before and during the information. The lack of understanding of the information system and the inability to use scientific inspection methods will also lead to the lack of rigorous information supervision.

\subsection{Insufficient information sharing capacity of government supervision departments}

Our government is mainly in charge of the financial department, audit department and tax department, but the supervision basis standards of the three departments are different, and the information between departments is lack of unified planning, which leads to the non transparency of enterprise information, the serious blockage of information resources, the low degree of sharing, the lack of understanding and authenticity, as well as the work content of simultaneous supervision between departments repetition, lack of communication, waste of unnecessary human and financial resources, so that the work efficiency is very low, which has a negative impact on the overall effect of government supervision.

\subsection{The comprehensive quality of accountants is not high}

Because the starting time of China's CPA is in 1991, China implemented the national unified examination system for CPA, while the Association of Chartered Certified Accountants in the UK (the Association of Chartered Certified Accountants) Accountants (ACCA) was founded in 1904. It is a leading professional accounting group in the world. Compared with other countries' CPA industry, China started late on poor foundation with little experience. In the past years, the degree of specialization of the staff in the accounting firm is not high. Although the number of people holding the qualification certificate of certified public accountant has increased year by year, the holders still lack of practical experience. Those who learn only the knowledge in books show a lack of a conscientious character in work, which can not meet the demand of highly professional accountants in China. It is hard for newcomers to resist the temptation of interests and to stand firm. Professional quality has greatly affected the efficiency and function of accounting supervision.

\section{Solutions of blockchain technology in the field of accounting supervision}

With the rapid development of modern economy and the improvement of management system, enterprises are gradually integrated into their economic activities under the global economic opening. Blockchain has been rapidly applied in many industries, but its popularity in the accounting field is not high, and its application scope is not wide. However, more and more accountants have invested in and learned about it, which is also very influential. At the same time, at the initial stage of learning blockchain technology application, the level of understanding of this technology is not high. Some problems have not been solved to a certain extent. Tracking the source of accounting information is crucial, so as to improve the overall supervision level, including accounting staff, relevant supervision departments and social supervision ${ }^{[3]}$.

\subsection{Open and transparent blockchain information management platform reduces the supervision of relevant government supervision departments}


(1) The relevant supervision departments of the government will be introduced into the blockchain system to publicize the progress of each supervision department's supervision objects. In this way, the work progress of each department will be open and transparent, which can not only ensure that all departments know the supervision status and information sharing of other departments at all times, but also communicate information adjustment and planning in time, so as to avoid repeated supervision with less human cost and financial cost, and then it can improve work efficiency.

(2) Although the government has strong credibility, there are still many problems in the words and deeds of some staff members. Citizens can monitor the work of relevant government departments through the key corresponding to the blockchain, so as to supervise the work in real time. At the same time, the work status of each supervision department is displayed in the process of work. If there is any problem in the supervision work, the responsible department can be found in time. To a certain extent, the supervision departments can avoid shirking responsibility, personal work inaction, irresponsible bureaucracy and other practices.

(3) Strengthen the supervision of public opinion. As a social citizen, supervision can promote the relevant supervision departments to perform their duties, and citizens should use reasonable ways to feed back to the relevant departments in a timely manner after discovering the relevant problems; as a media, it should shoulder social responsibility faced the problems in the supervision work directly. The supervision increases the exposure of violations of laws and disciplines. It dares to reveal unethical behavior and bad atmosphere in cooperation with accounting supervision wholeheartedly, which gives full play to the positive role of public opinion supervision.

\subsection{Blockchain's anti compilation and improvement of accountants' professional quality}

(1) Because of the irreversible nature of the anti editing in blockchain, for some new accountants and accountants who are vulnerable to the temptation of interests in the workplace, they may be limited by their own positions to do some acts against professional ethics. For example, the person in charge of the enterprise forcibly orders the accountants to conduct illegal operations, which is not conducive to the effective implementation of accounting supervision. Because the blockchain has the property of anti editing, as long as the data input by the accountant is successfully verified and included in the block, it is difficult to modify again. Once the input financial data is found to be asymmetric with the actual economic activity information, it will be severely punished by the company or even the relevant legal system. This kind of anti-editing nature greatly improves the preciseness and working position of accountants in their work. Distinguishing right from wrong, it improves the authenticity and security of financial data, which is an effective supervision method.

(2) Constantly improving our legal awareness is necessary. In today's society, it is common that accountants misappropriate public funds or they are bribed by the person in charge of relevant enterprises. It is necessary to strictly implement the relevant national financial accounting laws and regulations to correct their own world outlook, values and outlook on life. They be honest and fair without violations of laws and disciplines and false financial reports.

\section{Conclusion}

With the continuous development of technology, the new information technology not only brings us tremendous changes in our life and work, but also has further rational application of science and technology in the field of information technology. In the pursuit of higher information technology at the same time, China's accounting legal system is still not perfect. Before it is perfect, we should not only use blockchain technology to strictly supervise and restrict the scope of work of accounting personnel, but also pay attention to strengthen the supervision of enterprises. Relevant departments of the state should also adapt to the trend of the development of the times to modify the accounting legal system. Blockchain technology is constantly integrating into the field of accounting supervision, and employees in the accounting industry should also adapt to the changes brought by information technology. With better professional quality and moral cultivation, they need to continue learning to take the lead in the contemporary society. 


\section{References}

1. Tao L, Deng X. The application and research of blockchain technology in the field of accounting supervision (in Chinese). Commercial Accounting 2020; (4): 81-83.

2. Wang L. Construction of state-owned enterprise accounting supervision system (in Chinese). Ocean University of China 2004; $1-3$.

3. Liu L. On the causes and countermeasures of the weakening of accounting supervision (in Chinese). Northeast Normal University 2006; 1-3. 